\title{
Silicon and Boron Containing Components by CVD and CVI for High Temperature Ceramic Composites
}

L. Vandenbulke and M. Leparoux

Laboratoire de Combustion et Systèmes Réactifs, CNRS, 45071 Orléans cedex, France

\begin{abstract}
The potential large applications of ceramic composites require the preservation of their thermomechanical properties for long duration, in oxidative environments, under high temperature fatigue conditions and/or thermal cycling. This implies that the fibers and matrix properties, cracks deviation and load transfer at the fiber-matrix interface must be maintained. Different possibilities to progress in that way, that is to reduce the oxidation penetration in the parts or to improve the oxidation resistance at the fiber-matrix interface are examined. They include the use of protective external coatings, the development of new matrices or more oxidation resistant interphases. All components of the composite are examined successively. It appears that they are often composed of silicon and boron compounds, but more complex ternary or quaternary systems which include these two elements as compositional gradient materials or multilayered materials are developing. All these systems lead to some limitations of particular deposition or infiltration processes from the gas phase that are pointed out in view to some examples on the CVD and ICVI of ternary solids and multilayered materials, and on a comparison between CVD and ICVI processes for interphase elaboration. For each component of the composite, examples showing the improvement of the final properties are given. Finally we point out the domains where further research on deposition from the gas phase are needed.
\end{abstract}

\section{INTRODUCTION}

The desired properties of thermostructural non-oxide composite materials include some combinations of several properties like lightness, high mechanical resistance and toughness, oxidation resistance under thermal cycling conditions in ambient air or reduced pressure of molecular or atomic oxygen, resistance to degradation by moisture, resistance to erosion, and reusability. To reach these objectives, important studies concern the improvement of the ceramic fibers properties at high temperature $[1,2]$. On the other hand, many other studies have revealed the basic importance of the fiber/matrix bonding on the composite behavior. This bonding must be weak enough to allow crack deflection along the interface and strong enough to retain load transfer from matrix to fiber [3-5]. An additional coating, the interphase, is often intentionally inserted between the fiber and the matrix to reach this goal $[6,7]$. However, one important problem is to preserve the fibers and matrix integrity and to maintain the properties of cracks deviation and load transfer at the fiber/matrix interface, especially in oxidative environments, so as to retain the mechanical properties of the composite.

In this paper, different possibilities to progress in that way, that is to reduce the oxidation penetration in the parts or to improve the oxidation resistance at the fiber/matrix interface will be 
examined. They include the use of protective external coatings, the development of new matrices or more oxidation resistant interphases. Each component of the composite will be examined successively. It appears that they are often composed of silicon and boron compounds, but more complex ternary or quaternary systems that include these two elements or multilayered materials are developing. All these systems lead to some limitations of particular deposition or infiltration processes from the gas phase that will be pointed out in view to some examples taken from the literature or which come from our collaboration with the Société Européenne de Propulsion (SEP). Some results on the improvement of the final properties of different composites are also reported.

\section{OXIDATION-RESISTANT EXTERNAL COATINGS}

An extensive literature review of the protection against oxidation of any oxjdizible composite component by an external coating is far beyond the scope of this paper. Surface coatings have been first especially studied to protect carbon/carbon composites. These $\mathrm{C} / \mathrm{C}$ materials can be manufactured in a wide variety of structures and their properties are often anisotropic, especially their coefficients of thermal expansion (CTE). If a graphite grade with a CTE similar to a protective coating like $\mathrm{SiC}$ can be chosen [8], on the other hand it is more difficult to avoid any CTE mismatch with a $\mathrm{C} / \mathrm{C}$ composite and microcracks generally occur in the coating. Microcracks in the matrix are also produced in ceramic matrix composites (CMC) as a result of different CTE between the fibers and the matrix and these materials generally present also anisotropic properties. If they contain some oxidizible material, any damage is produced because of the oxygen diffusion through microcracks. Even if some closure of these cracks can occur as a function of temperature by formation of an oxide, others can be produced by stresses in the actual conditions of use. Single-layer coatings have been used first to try to overcome these problems.

\subsection{Single-layer coatings}

For example silicon carbide and nitride coatings have been extensively studied because the oxygen diffusion through solid silica formed at high temperature is relatively slow when compared to other oxides. However at very high temperature $\left(>1600^{\circ} \mathrm{C}\right)$ or medium temperatures and low oxygen partial pressures, a silica layer does not protect anymore because of either direct active oxidation ( $\mathrm{SiC}+\mathrm{O}_{2} \rightarrow \mathrm{SiO}+\mathrm{CO}$ ), or by reaction between silica and silicon carbide or nitride $\left(\mathrm{SiC}+2 \mathrm{SiO}_{2} \rightarrow 3 \mathrm{SiO}+\mathrm{CO}\right)$.

The actual applications domains of $\mathrm{CMC}$ are at lower temperature and a rapid rate of oxidation will proceed only if cracks do occur in these single-layer coatings as shown in figure 1 (sample $\mathrm{N}^{\circ} 207$ ) where a cyclic oxidation test was applied to a SiC-coated $\mathrm{C} / \mathrm{C}$ composite.

Single-layer coatings can be composite materials composed of several compounds. For example, ternary $(\mathrm{B}+\mathrm{Si}) \mathrm{N}$ coatings were deposited very recently from $\mathrm{BCl}_{3}-\mathrm{SiHCl}_{3}-\mathrm{NH}_{3}-\mathrm{H}_{2}$ mixtures [9]. As shown in figure 2 (from [9]), variation in the composition of the coating allowed to change its thermal expansion and to minimize the mismatch with the $\mathrm{C} / \mathrm{C}$ composite. Coatings with $2-35 \mathrm{wt} \%$ Si content were crack-free and they remained well bonded to the substrates. However the rates of oxidative weight loss of the coating, that decreased with increasing $\mathrm{Si}$ content, increased with time and the coating composition varied through vaporization of $\mathrm{B}_{2} \mathrm{O}_{3}$ from borosilicate glass. Blisters were accordingly observed at the surface after oxidation [9]. If boron oxide is an attractive compound for protection against oxidation because of its good wetting property and its low viscosity which allow the formation of thin protective glass films, the main limitations indeed arise from its vaporization at high temperature, from its flow under the influence of gravity or ablation, and its moisture sensitivity $[10,11]$. These problems are encountered when an outer borosilicate glass or a glass-former is employed as a sealant material at the surface.

A single-layer coating cannot be sufficiently efficient, especially under cyclic oxidation and/or to protect strengthened materials. Many complex coatings have been realized by CVD such as $\mathrm{Si}_{3} \mathrm{~N}_{4}+\mathrm{TiN}$ [12-14], $\quad \mathrm{Si}_{3} \mathrm{~N}_{4}+\mathrm{BN}[12,15], \quad \mathrm{Si}_{3} \mathrm{~N}_{4}+\mathrm{SiC}[12], \quad \mathrm{Si}_{3} \mathrm{~N}_{4}+\mathrm{AlN}[16], \quad \mathrm{SiC}+\mathrm{TiSi}_{2}[12,17], \quad \mathrm{SiC}+\mathrm{TiC}$ [18], 
$\mathrm{SiC}+\mathrm{HfB}_{2}$ [19], $\mathrm{AlN}+\mathrm{BN}$ [20], $\mathrm{ZrC}+\mathrm{BN}[21], \mathrm{TiB}_{2}+\mathrm{TiC}$ [22]. However few of them have been developed as protective coatings for composites and used in a multilayer concept.

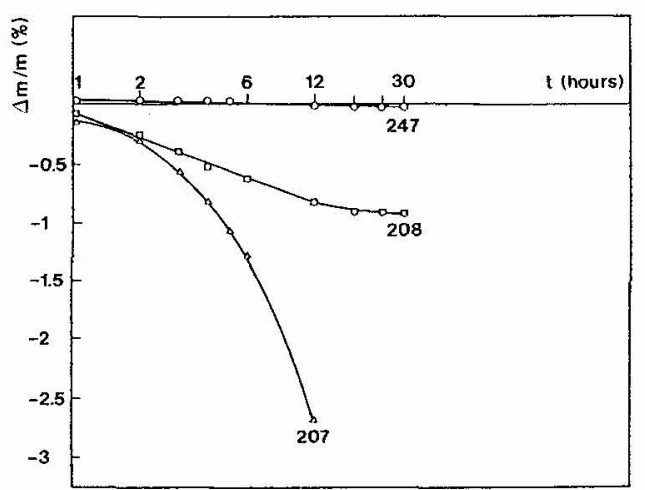

Figure $1: 3 \mathrm{D} \mathrm{C} / \mathrm{C}$ cyclic oxidation tests at $\mathrm{T}=1500^{\circ} \mathrm{C}$ in air $(\Delta \mathrm{m} / \mathrm{m}$ in wt\%);

207. $\mathrm{SiC}(160 \mu \mathrm{m})$

208. [(Si(50\%) B(10\%) C (40\%)] (180 $\mu \mathrm{m})$

247. $\mathrm{SiC}(180 \mu \mathrm{m})+[(\mathrm{Si}(30 \%) \mathrm{B}(40 \%) \mathrm{C}(30 \%)](60 \mu \mathrm{m})$

$+\mathrm{SiC}(60 \mu \mathrm{m})$; Percentages expressed in at $\%$.

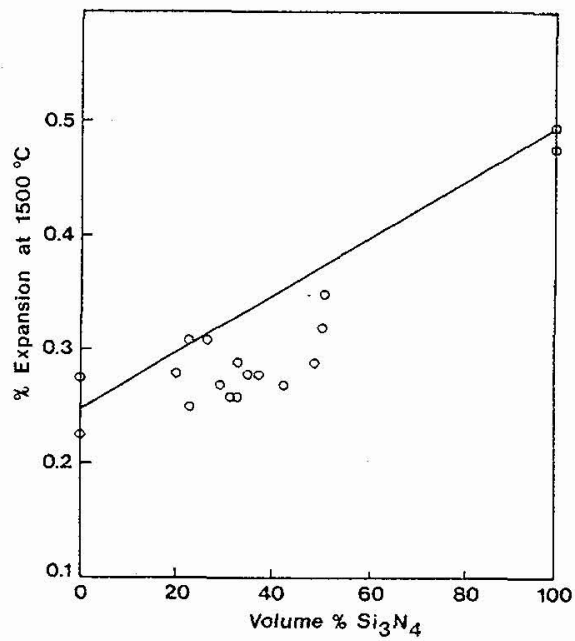

Figure 2 : Thermal expansion vs. volume $\% \mathrm{Si}_{3} \mathrm{~N}_{4}$ in $(\mathrm{B}+\mathrm{Si}) \mathrm{N}$ coatings (from [9]).

\subsection{Multilayer coatings}

The best protection can indeed be obtained by associating different but complementary ceramics that must take advantage of each layer while limiting its drawbacks. As seen previously, an outer borosilicate glass former will be rapidly oxidized at high temperature and the glass will be volatilized or will tend to flow under the influence of gravity or ablation. An internal position of the glass former would permit to restrict its formation within the cracks of the coating just where it is necessary. However it remains a possibility of direct contact between the glass and the matrix. In case of a $\mathrm{C} / \mathrm{C}$ composite it is interesting to insulate the substrate from the glass former and therefore to avoid the chemical reduction of the glass by carbon. For these reasons we have developed trilayer coatings composed of an internal SiC layer that is stable with respect to carbon, an intermediate $\mathrm{B}$ or $\mathrm{B}_{4} \mathrm{C}$ layer as a sealant glass former and an external $\mathrm{SiC}$ one, the oxidation kinetics of which is low in most conditions.

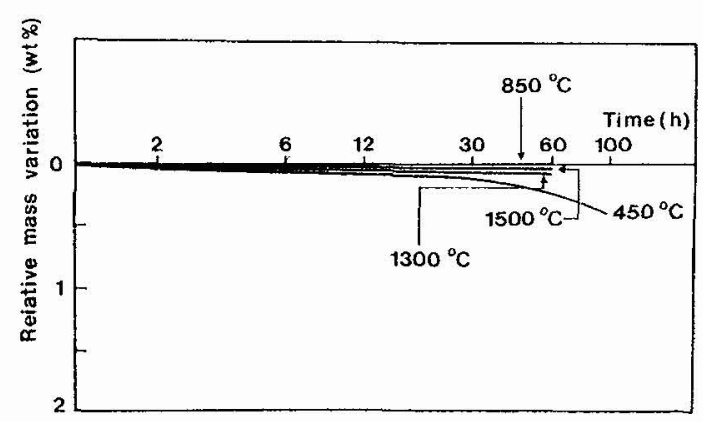

Figure 3 : Cyclic oxidation at various temperatures of 3D $\mathrm{C} / \mathrm{C}$ composites coated with $\mathrm{SiC}(120 \mu \mathrm{m})+\mathrm{B}_{4} \mathrm{C}(40 \mu \mathrm{m})+$ $\mathrm{SiC}(60 \mu \mathrm{m})$, in air at : a) 450 , b) 850 . c) 1300 . d) $1500^{\circ} \mathrm{C}$.

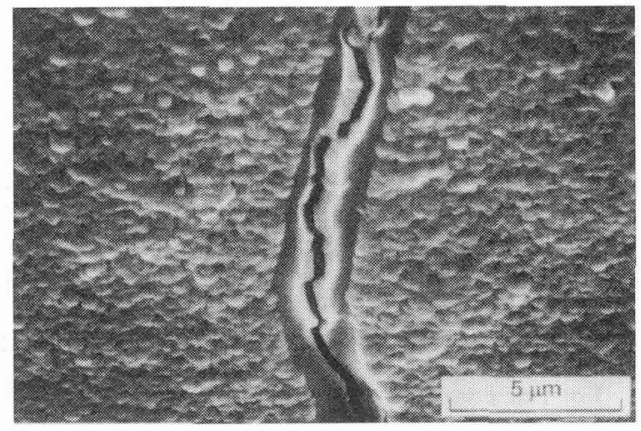

Figure 4 : Surface morphology after the cyclic oxidation test at $\mathrm{T}=850^{\circ} \mathrm{C}$. 
All these layers were deposited by CVD $[23,24]$ in conditions which are relatively classical from methyltrichlorosilane (MTS) $+\mathrm{H}_{2}$ and $\mathrm{BCl}_{3}+\mathrm{H}_{2}\left(+\mathrm{CH}_{4}\right)$. Figure 3 shows that such a multilayer coating deposited on a $\mathrm{C} / \mathrm{C}$ composite can be efficient in a large range of temperature, even here for cyclic oxidation, or under flexural loading [23]. One can note already here that thick coatings were employed. A good protection is also obtained with this coating type on $\mathrm{C} / \mathrm{SiC}$ composites [24]. A vitreous phase appears clearly in the cracks that were opened again when returning down to ambient temperature, either in the middle or on one side of the glass layer (fig. 4). At high temperature the composition of this glass could be self-adjusted by the volatilization of $\mathrm{B}_{2} \mathrm{O}_{3}$. The possibility of a subsequent sensitivity to moisture could not be avoided and a direct borosilicate glass former was studied, from the Si-B-C-H-Cl CVD system. The combination of the Si-B-C elements in one material appeared indeed promising if an accurate control of the composition could be obtained.

\section{$C V D$ study and protective coatings based on $S i-B-C$ :}

A thermodynamic approach was first undertaken to predict the composition of the $\mathrm{Si}-\mathrm{B}-\mathrm{C}-\mathrm{H}-\mathrm{Cl}$ system at equilibrium, and to determine the most interesting domain of the experimental parameters, especially the inlet composition [25]. A relatively high temperature of $1127^{\circ} \mathrm{C}$ was chosen to minimize the amount of departure from equilibrium at the gas-solid interface. Figure 5 presents the deposition diagram as a function of the inlet concentrations $\mathrm{MTS}, \mathrm{BCl}_{3}$ and $\mathrm{H}_{2}$ at $\mathrm{T}=1127^{\circ} \mathrm{C}$ and $\mathrm{P}=40 \mathrm{kPa}$ (300 Torr). The nature of the deposits is changed through the following ratios:

$$
\begin{aligned}
& \alpha=\left[\mathrm{H}_{2}\right]_{0} /[\mathrm{MTS}]_{0} \\
& \beta=[\mathrm{MTS}]_{0} /\left[\mathrm{BCl}_{3}\right]_{0}
\end{aligned}
$$

where $[X]_{0}$ represents the initial mole number of $X$ species. The equilibrium yields of the different gaseous and solid species were also obtained. They allow especially to calculate the solid composition at equilibrium that will be compared to the experimental results. For protection from oxidation, it is advisable to obtain deposits having no free carbon. Boron and silicon carbides are the most worthwhile phases because they should be deposited in a large range where the $\alpha$ and $\beta$ values are easy to control. From figure 5 , the experimental study area was chosen within the $\alpha=10-40$ and $B=0.6-8$ range.

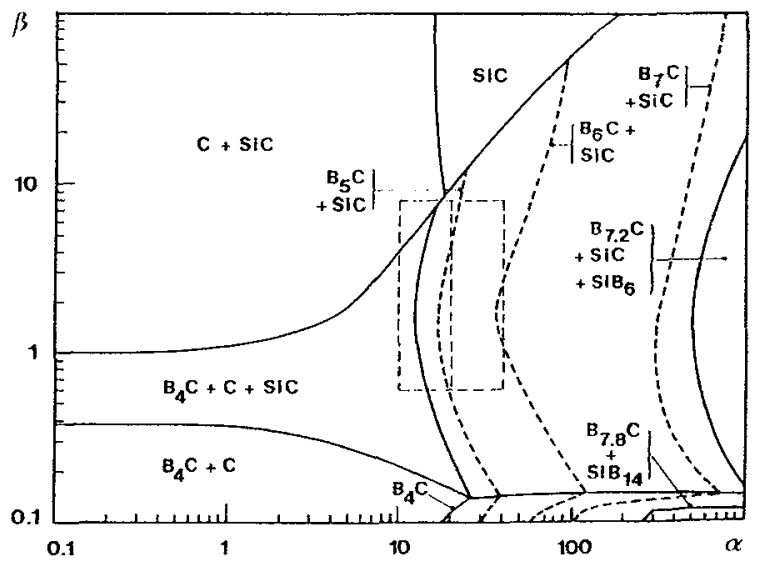

Figure 5 : Deposition diagram as a function of $\alpha$ and $\beta$ $\left(\mathrm{T}=1127^{\circ} \mathrm{C}, \mathrm{P}=40 \mathrm{kPa}\right.$ ).

High temperatures are known to favor the control by mass transport that is the rate-limiting step, but a classical direct comparison of the global thermodynamic calculations and experiments were made using this approach. First the influence of mass transfer on a local thermochemical equilibrium was neglected at the gas-solid interface where the material balance is changed by the element segregation transport phenomena $[26,27]$ or by the well-known reactant consumption and product formation at downstream positions inside the reactor, especially here in a hot-wall one. The experimental chemical compositions were measured at the bottom of the samples (the gas flow direction was upwards), at a short distance (about $3 \mathrm{~mm}$ ) from the lower edge, in order to minimize the reactant depletion and maintain the overall $\alpha$ and $\beta$ ratios as close as possible to the inlet ones. The curves in continuous lines represent the calculated compositions while the dashed lines, the experimental ones (fig. 6). The experimental and the 
thermodynamic values vary in the same way, but the incorporation of boron into the deposits was always greater than the predictions while the carbon incorporation was lower [28]. This discrepancy between the global equilibrium predictions and the experimental results may be due to the influence of fluid mechanical and chemical kinetics effects.

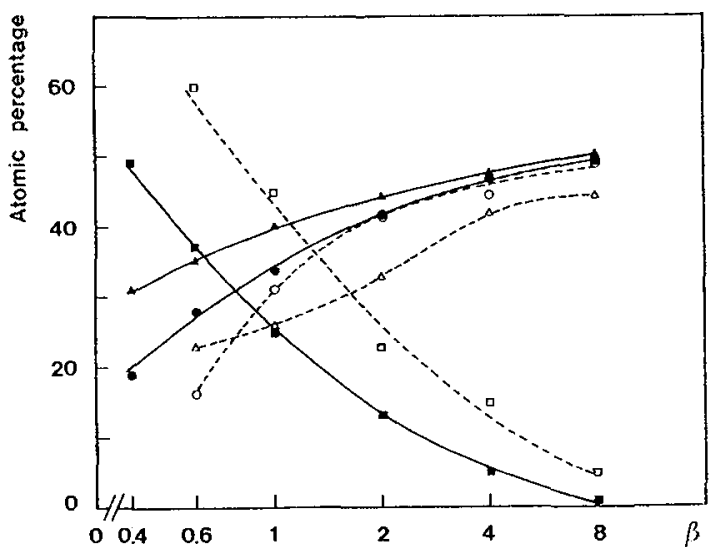

Fig. 6 : Comparison between the thermodynamic calculations and the experiments at $\alpha=20, \beta$ variable, $\mathrm{T}=1127^{\circ} \mathrm{C}, \mathrm{P}=40 \mathrm{kPa}$,

--- thermodynamic, - - experiment.

$\square$ Boron, $\Delta \Delta$ Silicon, $\bullet$ Carbon.

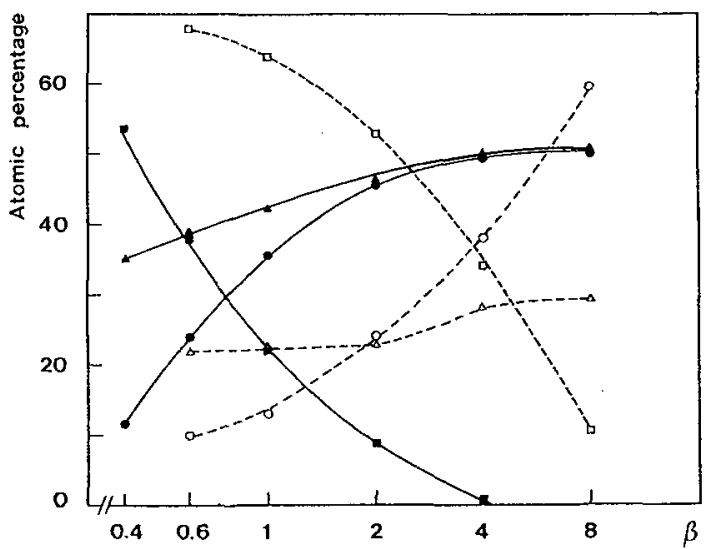

Fig. 7 : Comparison between the thermodynamic calculations and the experiments at $\alpha=20, \beta$ variable, $\mathrm{T}=927^{\circ} \mathrm{C}, \mathrm{P}=40 \mathrm{kPa}$,

--- thermodynamic, - - - experiment.

$\square$ Boron, $\Delta \Delta$ Silicon, 0 Carbon.

It is well known that the departure from equilibrium at the gas solid interface of a CVD system increases when the temperature decreases and the mass flow rate increases. Figure 7 compares the experimental results to the global thermodynamic predictions, at a temperature of $927^{\circ} \mathrm{C}$. A great departure from equilibrium was evidenced when the temperature decreased, showing especially a lack of carbon deposition, a well-known phenomenon in carbide deposition systems where free element incorporation is favored in comparison to carbide formation.

When the supersaturation varies, it influences both the thickness and composition in a multicomponent system, hence their uniformity along the surface. This evolution was observed for the codeposition of these three elements [29]. The influence of mass transport, consumption of reactants and product formation at downstream positions has been studied in the same deposition conditions as those reported in figure 6 . Neither the thickness nor the chemical composition was uniform for these deposition conditions at high temperature and consequently high rates (fig. 8). At lower temperatures and higher mass flow rates, clearly the deposition is more controlled by the surface kinetics and uniform thickness and composition are favored as shown in figure 9 that presents, for a temperature of $927^{\circ} \mathrm{C}$, the variations of the deposition rate and the solid composition as a function of the $B$ ratio and the position on the sample $(h$ in $\mathrm{mm}$ is the distance from the lower edge). However, in such a ternary system, the amount of departure from equilibrium may vary as a function of the inlet composition since different kinetic limitations can arise, especially here as a function of the relative concentration of the boron and silicon precursors. For example, from figure 9, it is clear that a higher amount of hydrocarbon species should be employed to deposit $\mathrm{C}$-rich coatings while a lower temperature should be necessary to deposit uniform Si-rich layers. 


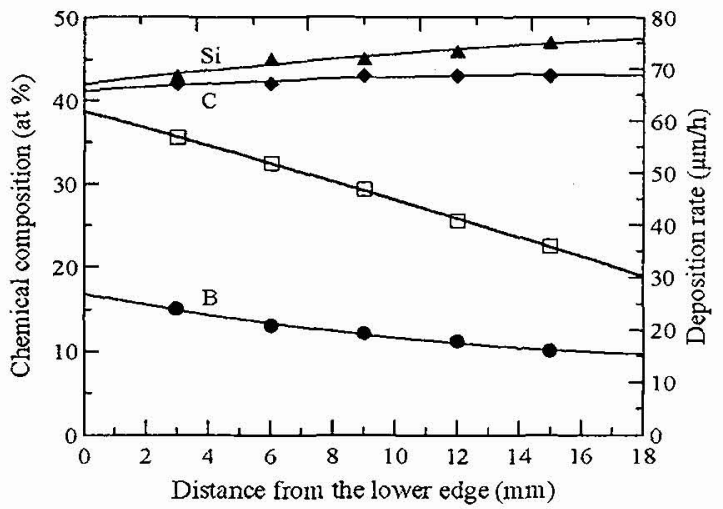

Figure 8 : Variations of the chemical composition and the deposition rate as a function of the distance along the substrate ( $T=1400 \mathrm{~K}, \mathrm{P}=40 \mathrm{kPa}, \alpha=20, \beta=4)$.

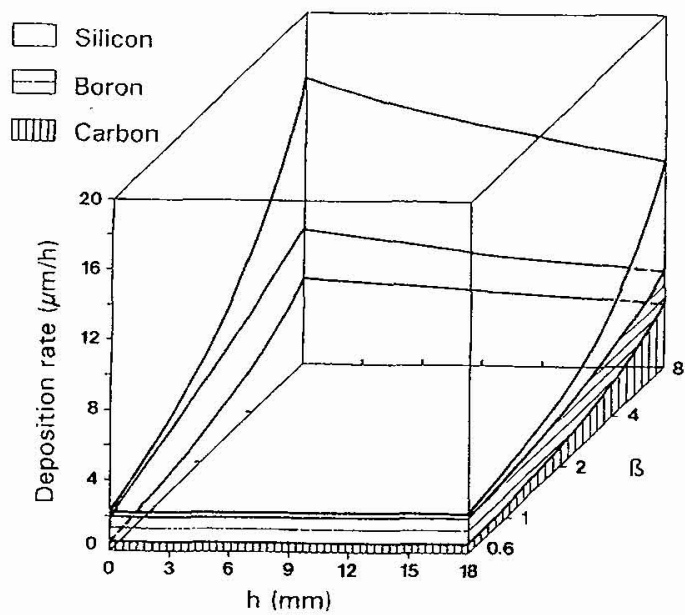

Figure 9: Variations of the chemical composition and the deposition rate as a function of $\beta$ and the distance along the substrate $(\mathrm{T}=1200 \mathrm{~K}, \mathrm{P}=40 \mathrm{kPa}, \alpha=20$ ).

In a first attempt, single-layers containing the three elements (Si-B-C) or dual-layers $(\mathrm{SiC}+$ outer $\mathrm{SiBC}$ ) were tested in an oxidizing atmosphere to protect $2 \mathrm{D} \mathrm{C} / \mathrm{SiC}$ or $3 \mathrm{D} \mathrm{C/C}$ composites. As for $\mathrm{SiBN}$ coatings, a rapid oxidation of the external $\mathrm{SiBC}\left(50 \mathrm{at} \% \mathrm{Si}-10 \% \mathrm{~B}-40 \% \mathrm{C}\right.$ ) layer occurs at $1500^{\circ} \mathrm{C}$ (fig. 1) and an important blistering was observed (fig. 10a). A fracture of a similar $\mathrm{C} / \mathrm{SiC}$ sample shows the porosity of the oxide layer and the tubular morphology of the $\mathrm{SiC}$ matrix after oxidation of the carbon fibers (fig. 10b). Then, a solution based on a multilayer : SiC internal layer, (Si-B-C) intermediate layer and $\mathrm{SiC}$ external layer has been developed and tested up to temperatures of about $1600^{\circ} \mathrm{C}$ [30]. Figure 1 compares the results of cyclic oxidation tests carried out on $3 \mathrm{D} \mathrm{C} / \mathrm{C}$ at $1500^{\circ} \mathrm{C}$ (samples were put inside and taken out a furnace in about 30s for 6 cycles of one hour followed by 4 cycles of 6 hours) with the previous results obtained with the single-layer Si-B-C coating with a low boron content $(10$ at $\% \mathrm{~B})$ and the $\mathrm{SiC}$ layer. Better results were obtained with a multilayer coating that include an intermediate Si-B-C layer which contains more boron $(30 \% \mathrm{Si}-40 \% \mathrm{~B}-30 \% \mathrm{C})$, and an intrinsically more resistant pure $\mathrm{SiC}$ external layer. Such multilayer coatings can operate in a large range of temperature if the boron content is sufficiently high to allow sealing of the cracks by internal glass formation while retaining the intrinsic oxidation resistance of the external $\mathrm{SiC}$ layer. Thick $\mathrm{SiC}$ inner and outer layers might limit the interaction with the substrate and the volatilization of boron oxide respectively.

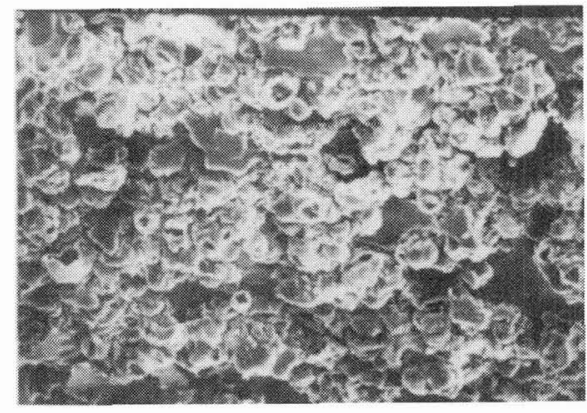

(a)

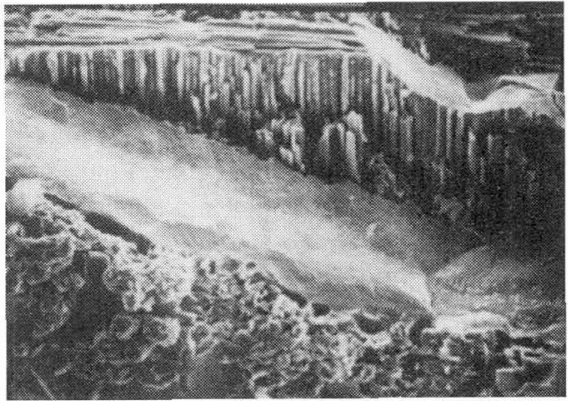

(b)

Figure $10:$ a) Surface morphology and b) morphology of a fracture of a 2D C/SiC coated with dual layers of $\mathrm{SiC}(60 \mu \mathrm{m})+$ $\left[(\mathrm{Si}(50 \%) \mathrm{B}(10 \%) \mathrm{C}(40 \%)](70 \mu \mathrm{m})\right.$, after a $10 \mathrm{~h}$ cyclic oxidation test at $1500^{\circ} \mathrm{C}$. 


\subsection{Remarks on the CVD process}

Regarding the CVD process itself, it may be noted first that all multilayer coatings cannot be easily deposited because of possible extensive initial interaction between a layer and the gaseous phase employed to deposit the next one. For example, the deposition of $\mathrm{BN}$ from $\mathrm{BCl}_{3}-\mathrm{NH}_{3}-\mathrm{H}_{2}$ mixtures is difficult on $\mathrm{ZrC}$ owing to the important formation of zirconium chlorides in classical conditions of deposition [31].

On the other hand, it has been shown previously that fairly uniform coatings were obtained on small substrates at relatively high deposition rates (several microns per hour) that could not be reached in a large scale hot-wall reactor without paying careful attention to the fluid flow dynamics as already shown by many authors, even in binary systems, for example in experimental SiC deposition [32,33]. A particular care would be necessary especially because thick coatings are required to improve the protection.

The influence of the total pressure is well known to increase the surface kinetic control of the deposition process. This point is interesting for depositing coating in industrial reactors, except that longer deposition times could be necessary. It is especially important to extend the deposition process to isothermal chemical vapor infiltration (ICVI).

\section{SELF-PROTECTIVE MATRICES}

The protection by an external coating is inadequate for applications where some damage can arise by mechanical impact. For that reason, various glass formers have been added first to the carbon matrix of $\mathrm{C} / \mathrm{C}$ composites in order to fill in the cracks. Boron and silicon compounds, mainly $\mathrm{B}, \mathrm{B}_{4} \mathrm{C}, \mathrm{ZrB}_{2}, \mathrm{AlB}_{12}$, $\mathrm{SiB}_{14}, \mathrm{ZrB}_{2}+\mathrm{Si}, \mathrm{SiC}$, were generally added to the carbon matrix by various methods, generally from liquid or solid phases. However, this protection is poor and can only be employed in addition to an external one (see review [8]).

Non-oxide ceramic matrices that increase the oxidation resistance of the composites have been studied for many years since the pioneering works of European groups [34-39]. With regard to the deposition processes, efforts were concentrated first on the isothermal chemical vapor infiltration (ICVI) of $\mathrm{SiC}$ and to a lesser extent of $\mathrm{Si}_{3} \mathrm{~N}_{4}$. The feasibility of the CVI process of other compounds like $\mathrm{B}_{4} \mathrm{C}$, $\mathrm{BN}, \mathrm{ZrB}_{2}, \mathrm{TiC}$ has also been established [39]. Many studies were devoted to the understanding and the optimization of the infiltration processes based first on the modeling of the deposit thickness profile along a single pore [40-42]. More recent models allow one better to predict tendencies for the influence of important parameters on the CVI processes [43-54]. They have used representations of the complex fiber architecture and expressions for mass and heat transfer (in non-isothermal systems) coupled to chemical kinetics. However an accurate modeling of the CVI processes remains a difficult task, because the influence of local gaseous partial pressures of both reactants and products should be generally employed in the expression of the surface kinetics, some homogeneous chemical reactions can occur, and the problem depends on the type and the amount of porous preform set in a given deposition zone, finally the pore size distribution changes with time.

It is not yet in the scope of this paper to review the literature on the chemical vapor infiltration processes extensively. Only the limitations of single-compound matrices employed in oxidizing environments will be examined and some progress offered by more complex matrices indicated. Then the CVI techniques will be regarded as a function of their ability to permit the infiltration of such matrices.

\subsection{Non-oxide ceramic matrices in oxidizing environments}

The oxidation kinetics of various ceramic matrix composites has been reported, especially the most common $\mathrm{C} / \mathrm{SiC}$ and $\mathrm{SiC} / \mathrm{SiC}$ that represent potential candidates for use at high temperature. For example, the oxidation kinetics of $\mathrm{SiC}$-coated $2 \mathrm{D} \mathrm{C} / \mathrm{SiC}$ composites with a pyrocarbon interphase has been 
extensively studied $[55,56]$. In that case, matrix microcracking already occurs from the CTE mismatch between the fibers and the matrix as shown schematically in figure 11 (from [56]). The experimental mass variations of these $\mathrm{C} / \mathrm{SiC}$ materials as a function of temperature are given in figure 12 (from [56]). The authors concluded that different processes arose as a function of temperature : - at moderate temperature the carbon/oxygen surface reaction controls the oxidation kinetics; - at intermediate temperature $(800$ $1100^{\circ} \mathrm{C}$ ), the rate limiting step is the gaseous diffusion through microcracks ; - finally as the temperature rises the oxygen diffusion decreases with growth of the silica layer. The oxidation kinetics is reduced with a thicker SiC coating that minimizes the oxygen flux. On the contrary, an applied tensile stress opens the microcracks and decreases the sealing effect which therefore only appears at higher temperatures [56]. It can be noted that these $\mathrm{C} / \mathrm{SiC}$ materials can sustain high temperatures because of the mechanical properties of the carbon fibers, and lifetime is function of the carbon consumption.

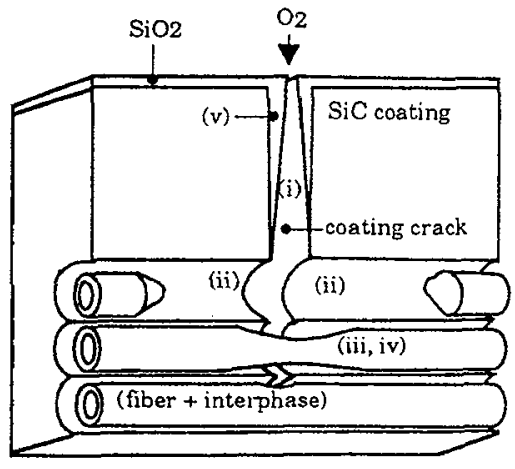

Figure 11 : $\mathrm{SiC}$ external coating and matrix microcracking during high temperature oxidation (from [56]).

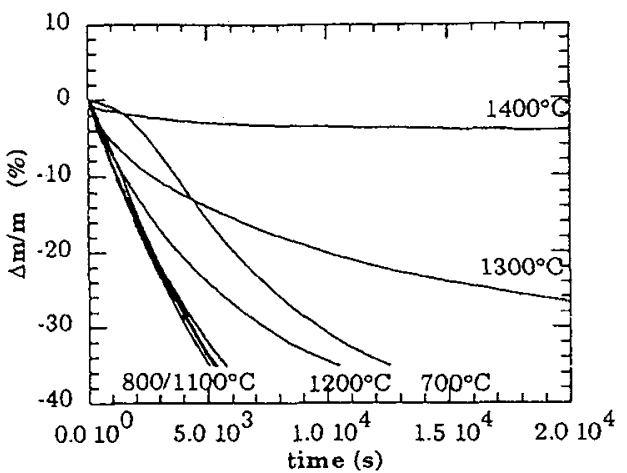

Figure 12 : Mass variations of $\mathrm{SiC}$-coated $\mathrm{C} / \mathrm{SiC}$ composites in oxygen $(\mathrm{P}=100 \mathrm{kPa})$ as a function of time and temperature (from [56]).

$\mathrm{SiC}(\mathrm{O}) / \mathrm{C} / \mathrm{SiC}$ materials, composed of $\mathrm{Si}-\mathrm{C}-(\mathrm{O})$ fibers such as ${ }^{1} \mathrm{Nicalon}^{\mathrm{TM}}$, a pyrocarbon interphase and a silicon carbide matrix (designated as $\mathrm{SiC} / \mathrm{C} / \mathrm{SiC}$ in the following) can be used at lower temperatures, up to about $1200^{\circ} \mathrm{C}$ where the strength of Nicalon fibers decreases. The reactivity of uncoated composites after machining was studied in oxygen, in the $900-1200^{\circ} \mathrm{C}$ range [57]. Only the highest temperature permits the sealing of the interfacial cavities left after partial gaseification of the pyrocarbon interphase. Protection of the fibers tips by an outer $\mathrm{SiC}$ layer would be effective for such test as these materials do not present microcracks. However many potential applications for these composites will involve creep loading that may be tensile, flexural or compressive in nature. Under such actual conditions of use, matrix cracks will be initiated again for a threshold stress [58].

More complex matrices have been elaborated tentatively to overcome this problem. Their manufacturing is often complicated, as it combines different types of processes (for example infiltration by slurry and CVI) to enrich the matrix in glass-former elements like boron [59-61].

As shown in the previous section on the external coating, the manufacture of a composite or multilayered material can be better monitored by deposition from the gaseous phase. The ternary SiBC coating was chosen as one layer and could be associated with $\mathrm{SiC}$ to produce a self-protecting matrix in a large temperature range, especially at lower temperature than pure $\mathrm{SiC}$. The process for the manufacture of a refractory composite material with a $\mathrm{SiBC}$ matrix type has been patented by SEP [62]. Such a $\mathrm{SiC} / \mathrm{C} /(\mathrm{SiC}+\mathrm{SiBC})$ composite material with a pyrocarbon interphase was tested at room temperature or at $850^{\circ} \mathrm{C}$, in air, under creep (using the four-point bending fixture) at different stresses ranging from 150 to $200 \mathrm{MPa}$. Table I reports the results of these tests. They are compared with those obtained on samples made of a classical $\mathrm{SiC} / \mathrm{C} / \mathrm{SiC}$ composite. The sustain flexing strain exerted on the composite material led

\footnotetext{
${ }^{1}$ Nicalon ${ }^{\mathrm{TM}}$ : Nippon Carbon, Japan
} 
to important microcracking of the matrix. Table I shows the important improvement of the protective effect due to the $\mathrm{SiBC}$ addition to the matrix through $\mathrm{SiBC} / \mathrm{SiC}$ sequences.

\begin{tabular}{|c|c|c|}
\hline Material & $\begin{array}{c}\text { Stress to rupture at room temperature } \\
\text { (four-point bending test) }\end{array}$ & $\begin{array}{c}\text { Test in air at } 850^{\circ} \mathrm{C} \\
\text { (creep test) }\end{array}$ \\
\hline $\begin{array}{c}\text { SiC reinforcement } \\
\text { SiC+SiBC sequenced matrix }\end{array}$ & $420 \mathrm{MPa}$ & $\begin{array}{c}\text { No rupture after } 100 \text { hours } \\
\text { under creep at } 150 \mathrm{MPa}\end{array}$ \\
\hline $\begin{array}{c}\mathrm{SiC} \text { reinforcement } \\
\mathrm{SiC}+\mathrm{SiBC} \text { sequenced matrix }\end{array}$ & $420 \mathrm{MPa}$ & $\begin{array}{c}\text { No rupture after } 100 \mathrm{hours} \\
\text { under creep at } 180 \mathrm{MPa}\end{array}$ \\
\hline $\begin{array}{c}\mathrm{SiC} \text { reinforcement } \\
\mathrm{SiC}+\mathrm{SiBC} \text { sequenced matrix }\end{array}$ & $420 \mathrm{MPa}$ & $\begin{array}{c}\text { No rupture after } 100 \mathrm{hours} \\
\text { under creep at } 200 \mathrm{MPa}\end{array}$ \\
\hline $\begin{array}{c}\mathrm{SiC} \text { reinforcement } \\
\mathrm{SiC} \text { matrix }\end{array}$ & $300 \mathrm{MPa}$ & $\begin{array}{c}\text { Rupture after } 14 \mathrm{hours} \\
\text { under creep at } 150 \mathrm{MPa}\end{array}$ \\
\hline
\end{tabular}

Table I : Flexural creep behavior at room temperature and $850^{\circ} \mathrm{C}$ of a $2 \mathrm{D} \mathrm{SiC} / \mathrm{C} /(\mathrm{SiC}+\mathrm{SiBC})$ composite compared to a $2 \mathrm{D}$ $\mathrm{SiC} / \mathrm{C} / \mathrm{SiC}$ classical composite (from [62]).

\subsection{Remarks on the infiltration processes}

The general classes of CVI techniques are well known [63]. The isothermal-isobaric (ICVI) technique was developed at first, both on a laboratory scale and then on a commercial basis. The process involves the diffusion of the reactants and gaseous products within the porous preform. An appropriate deposit uniformity inside the preform is obtained by a careful deposition rate control at reduced pressure and sufficiently low temperature to limit the chemical kinetics more than the diffusion. The process time must be ajusted to limit the sealing of the pore entrance. However the ICVI permits to use various preform geometries in large scale reactors, and different deposition conditions to fill the fine porosity within the bundles and to infiltrate the coarser ones between them.

The isobaric-thermal gradient process allows to avoid any sealing of the entrance of the pores. However it is still a process where the transfer depends on diffusion only. A temperature profile that favor the « inside-out 》 densification of the composite without residual accessible porosity can be produced by volume heating of the preform by microwave or radio frequency induction [54].

The other important class of processes are based on forced flow. Isothermal processing is essentially interesting to coat tows or $2 \mathrm{D}$ single-cloth at high rates, in conditions that do not depart very much from CVD. The forced flow-thermal gradient (FCVI) technique developed at the Oak Ridge National Laboratories permits to increase considerably the densification rate of thick parts $[64,65]$. It is however more restricted to individual parts and simple shapes than the ICVI processes, especially because each preform geometry necessitate an appropriate tool to force reactants to flow through the preform.

The pulsed-flow technique (PCVI) utilizes multiple sequences of introduction of reactants and evacuation of the reactor. This process allows to transport the reactant species into the preform and to evacuate the gaseous products rapidly [66-68]. An improvement of the infiltration rate is questionable, but this process permits to modify the gas phase composition through homogeneous chemical reactions by the control of the residence time from the pulse monitoring. The deposit structure can then be optimized as shown for pyrocarbon [68]. It is noteworthy also that PCVI is an isothermal process.

All CVI processes that employ a thermal gradient have been used to infiltrate matrices with binary compounds like SiC where the deposition conditions of a stoichiometric compound are not too critical. As shown in section 2.2 on SiBC, the deposition of a ternary coating of desired composition is somewhat more difficult to control. Especially a uniform composition could not be generally obtained in a temperature gradient. Moreover in any case, the thermal gradient-based processes do not permit obviously 
to infiltrate the whole preform at fairly uniform rate. A multilayered material therefore cannot be manufactured by FCVI. For all these reasons, only the ICVI and PCVI processes can be used to infiltrate the preform with complex improved matrices. This remark is also valid for coating all fibers of the preform with an interphase of uniform thickness and composition by an infiltration process.

\section{IMPROVED INTERPHASES}

The best mechanical behaviour of ceramic matrix composites at room temperature has been mainly obtained with a pyrocarbon interphase, but the efficiency of these carbon interlayers is limited at high temperature to non-oxidizing environments. When a crack propagates through the matrix till the interphase, the carbon interphase is obviously oxidized in air; the result is either a detachment at its interface with the fiber, and/or the formation of a glassy oxide layer that bonds strongly the fiber to the interphase [ ]. In anyway, bonding at this interface will be too weak or too tight leading in both cases to inadequate thermomechanical properties of the composite.

\subsection{Modified pyrocarbon interphases}

Efforts have been made to improve the oxidation resistance of the carbon interphase. Multilayered $\mathrm{C} / \mathrm{SiC}$ interphases that permit more crack deflections [69] have been developed but, today they might just rather delay the access of oxygen to the fiber/interphase interface and so the oxidation at high temperature. In other studies, the oxidation resistance of the pyrocarbon interphase is improved by some change of its composition as in boron-doped pyrocarbon [70] or in compositional gradient (CG) layer in which the composition varies continuously from $\mathrm{C}$ (at the fiber interface) to $\mathrm{SiC}$ (at the matrix interface) [71]. These CG layers were deposited by ICVI, at $770^{\circ} \mathrm{C}$ and $6 \mathrm{Torr}$, from tetraethylsilane and the addition of cumene, ${ } \mathrm{PrC}_{6} \mathrm{H}_{5}$ that permitted a C-enrichment [72]. Figure 13 (from [71]) shows that this interphase allows to preserve the mechanical properties after aging in air at $1300^{\circ} \mathrm{C}$. However no oxidation test was carried out in air at a significant stress level.

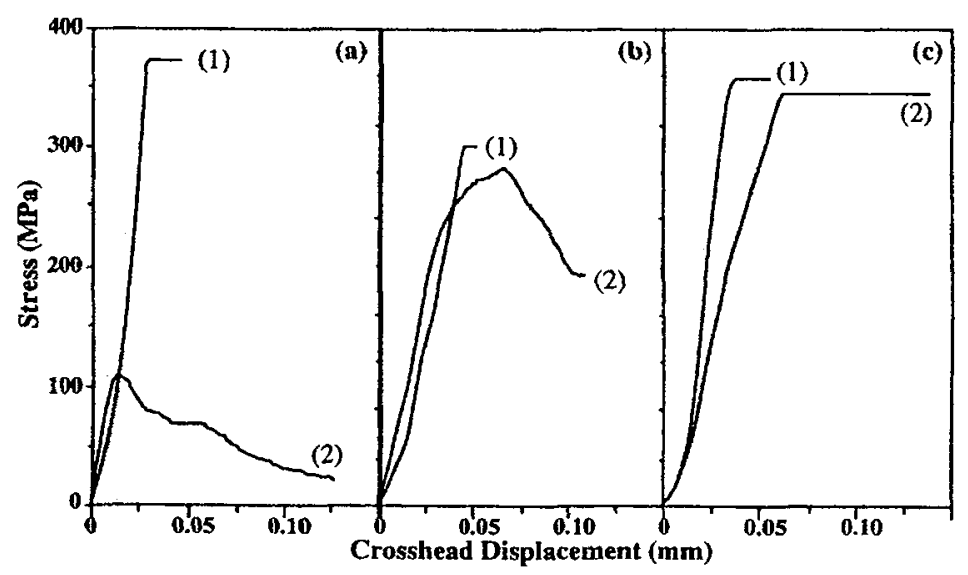

Figure 13 : Stress-displacement curves from four point flexure testings at $25^{\circ} \mathrm{C}$ before (1) and after (2) oxidation in air at $1300^{\circ} \mathrm{C}$ during $20 \mathrm{~h}$ for different fibers/matrix interface treatments : a) Pyrocarbon, b) $\mathrm{Si}_{0.25} \mathrm{C}_{0.75}, \mathrm{c}$ ) $\mathrm{CG}$ layer from $\mathrm{C}$ to SiC (from [71]).

\subsection{Boron nitride interphases}

On the other hand, boron nitride has been proposed as an alternative because of its graphite-like structure and its better resistance toward oxidation $[73,74]$. Particular attention has been heeded to the interfacial zones in terms of chemistry and microstructure $[7,75]$. These studies revealed that when $\mathrm{SiC}$ 
fibers, as Nicalon ${ }^{\mathrm{TM}}$ or ${ }^{2} \mathrm{Ty}^{2} \mathrm{nnno}^{\mathrm{TM}}$, are coated with $\mathrm{BN}$, many interfacial $\mathrm{C}$ and/or $\mathrm{SiO}_{2}$-rich sublayers can be present between the fiber and the boron nitride film [76]. To improve the mechanical properties, especially at high temperature, it is primordial either to protect the C-rich sublayers from the external atmosphere, or still better to prevent their development. In the first case, cracks that occur when the composite is submitted to significant stress must be deflected in the laminar structure of the interphase to prevent any oxygen diffusion from the external environment to this carbon-rich interface. This implies the formation of a strong interface bonding and an optimized organization of the BN interphase. Additionally, it is reasonable to think that an improvement of the BN lattice organization should lead to better mechanical properties in any conditions. Such an optimized microstructure can be searched by controlling the chemical vapor deposition process.

Various precursors have been used to deposit boron nitride, like borazine $\mathrm{B}_{3} \mathrm{~N}_{3} \mathrm{H}_{6}$ [77] or $\beta$ trichloroborazine $\mathrm{B}_{3} \mathrm{~N}_{3} \mathrm{H}_{3} \mathrm{Cl}_{3}$ [78] but also mixtures of $\mathrm{NH}_{3}$ with diborane $\mathrm{B}_{2} \mathrm{H}_{6}$ [79] or with boron halides [80-83]. Since diborane requires much care in handling, halides as $\mathrm{BF}_{3}$ and $\mathrm{BCl}_{3}$ are often preferred. Composites with good strength and toughness have been obtained with a $\mathrm{BN}$ interlayer, particularly when the deposition is carried out from $\mathrm{BCl}_{3}-\mathrm{NH}_{3}-\mathrm{H}_{2}$ mixtures at relatively high temperature, in conditions of forced flow through tows of small diameter, in conditions approaching the CVD process [84]. However the direct deposition within the fibrous preform is generally preferred. As shown previously, the ICVI process can be used, but it requires a lower deposition temperature to allow the deposition of sufficiently uniform layers on all fibers [83]. The most stable $\mathrm{BF}_{3}-\mathrm{NH}_{3}$ mixture was used first at about $1000^{\circ} \mathrm{C}$ [81], but this gaseous phase is corrosive especially for Si-C-(O) fibers such as Nicalon ${ }^{\mathrm{TM}}$ [81].

A thorough study of the ICVI of BN was carried out more recently, in conditions that could be used in a large scale reactor, while utilizing the $\mathrm{BCl}_{3}-\mathrm{NH}_{3}-\mathrm{H}_{2}$ mixture that is less corrosive than the fluoride-containing mixture [85]. However, its higher kinetics requires to use a lower temperature, in the $500-700^{\circ} \mathrm{C}$ range, to obtain a good infiltration $[83,85]$. The variation of the nanostructure of $\mathrm{BN}$ coatings deposited by different chemical vapor processes was reported as a function of various parameters including the process type (CVD or ICVI), the fiber nature and the processing parameters [86]. Some results on this study are reported here together with the final properties of the composite materials.

\section{CVD and ICVI of boron nitride from $\mathrm{BCl}_{3}-\mathrm{NH}_{3}-\mathrm{H}_{2}$ mixtures}

In order to gain some insight in the deposition conditions we report first the results of the influence of the total mass flow rate on the deposition rate obtained with both CVD and ICVI processes.

The deposition apparatus and procedure have been described in detail previously [83]. BN deposition was carried out simultaneously on a fibrous preform and on a bulk substrate to investigate both ICVI and CVD. One bulk substrate was composed of ten graphite rings mounted on a holder, in the flow direction. They allow to study the CVD process, especially the longitudinal thickness uniformity. The infiltration process (ICVI) was investigated by using 3D woven architecture (Novoltex) made with $9 \mu \mathrm{m}$ carbon fibers (ex-PAN treated by SEP) which led to a material with an average pore diameter of $45 \mu \mathrm{m}$ and a specific surface of $0.25 \mathrm{~m}^{2} / \mathrm{g}$. The fibrous preform $\left(150 \times 18 \times 10 \mathrm{~mm}^{3}\right)$ consisted of 30 intermediate samples which allowed to characterize the deposit longitudinal and infiltration uniformities (LU is the longitudinal thickness uniformity, IU is the infiltration uniformity and TU is the total uniformity defined as $\mathrm{TU}=[\mathrm{LU} \times \mathrm{IU}])$. The results reported here were obtained with diffusion screens. They allow to create a pure diffusive volume around the porous preform that were separated from the convective flow. For the bulk substrate, $\mathbf{U}$ is the longitudinal uniformity calculated as the ratio between the relative weight increase at the bottom and at the top of the ten graphite rings after smoothing the curve that reports the relative weight gain of the ten substrates.

\footnotetext{
${ }^{2}$ Tyranno $^{\mathrm{TM}}:$ UBE Industries, Japan

${ }^{3}$ Novoltex : SEP, France
} 
It must be noted that the relative weights of deposit measured on the bulk and the fibrous substrates are not directly comparable in terms of real deposition rates. It is obvious that the CVD rates are always higher than the ICVI ones. In our case, the total surface to be coated on and inside the preform is about 440 times more important than the surface of the bulk substrate.

Figure 14 reports the variations of the relative weight gains of the preform and the bulk substrate as a function of the total mass flow rate $\left(\mathrm{T}=700^{\circ} \mathrm{C}, \mathrm{P}=10\right.$ Torr, $\mathrm{NH}_{3} / \mathrm{BCl}_{3}=1$ and $\left.\mathrm{H}_{2} / \mathrm{BCl}_{3}=1\right)$. The ICVI deposition rate is always increasing while the CVD one tends to level off. Above flow rates of about $1.5 \mathrm{~g} / \mathrm{min}$, the deposition kinetics appears mainly controlled by the heterogeneous kinetics at the surface of the bulk substrate as shown either by the negligible influence of the total flow rate and by the very high value $(98 \%)$ ) of the longitudinal uniformity (figure 15 ). The influence of the mass flow rate on the CVD deposition rate can be therefore attributed to a transition in the process from a mass transfer plus chemical kinetics control to a pure chemical kinetics limitation. In the preform, the thickness uniformities stay nearly constant at quite high values, of about $70 \%$ longitudinally and $80 \%$ in infiltration, for flow rates greater than about $0.5 \mathrm{~g} / \mathrm{min}$. Below this flow rate, the reactants are used soon in the external and upper part of the preform and lower uniformities are obtained. From figures 14 and 15, clearly the ICVI process is always governed by a combination of mass transfer and chemical kinetics.

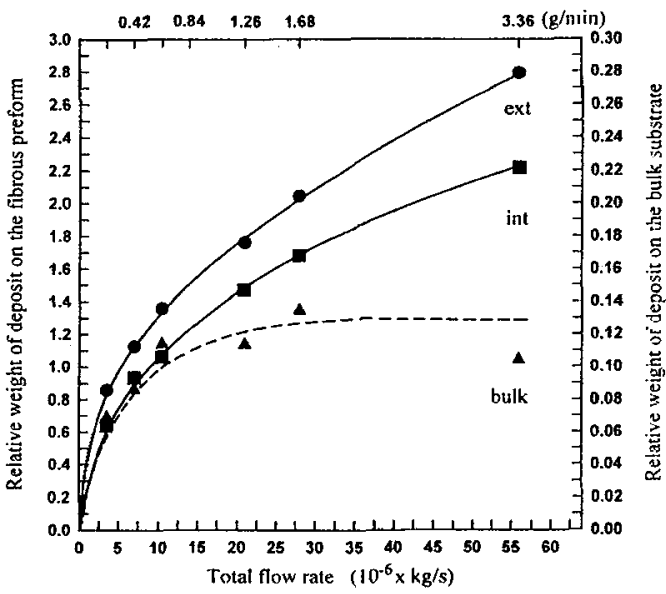

Figure 14 : Influence of the total flow rate on the relative weight of deposit $(\Delta \mathrm{m} / \mathrm{m})$ on the bulk substrate and in the fibrous preform (internal and external parts) obtained for $\mathrm{T}=700^{\circ} \mathrm{C}, \mathrm{P}=10$ Torr, $\mathrm{NH}_{3} / \mathrm{BCl}_{3}=1$ and $\mathrm{H}_{2} / \mathrm{BCl}_{3}=1$.

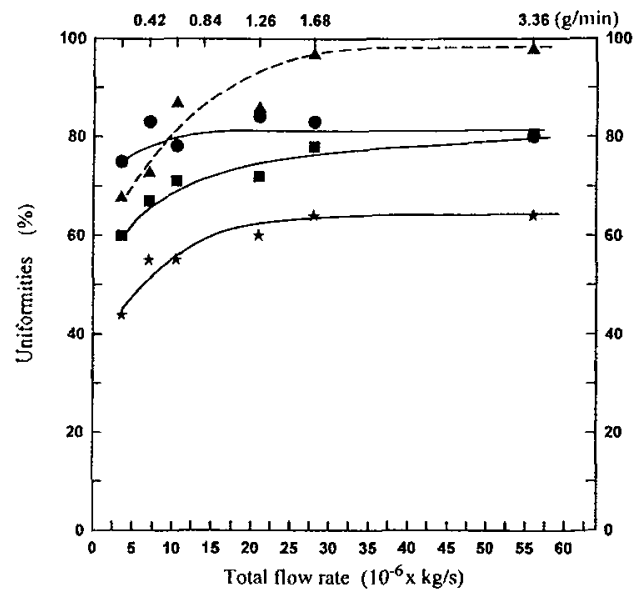

Figure 15: Variation of the uniformities with the total flow rate on the bulk substrate $U(\Delta)$ and in the preform LU (a), IU (•), TU(*).

As high flow rates lead to deposition conditions where the CVD process is only controlled by the surface kinetics the CVD mechanism can be studied and the deposition conditions in the ICVI process can be compared.

It has been first verified that argon had no influence on the chemical kinetics [86]. The nil order with respect to argon allowed then to maintain constant both the total flow rate and the total pressure (8 Torr) by addition of $\mathrm{Ar}$, while the partial pressure of a species was changed to determine the apparent reaction order with respect to this species. In these conditions, the residence time of the gaseous phase within the reactor was kept constant and the variations of the diffusion conditions were restricted to the compositional effect. The apparent reaction order with respect to the gaseous product $\mathrm{HCl}$ was observed to be zero, according to a previous conclusion [85]. The influence of $\mathrm{BCl}_{3}$ and $\mathrm{NH}_{3}$ partial pressures are respectively illustrated in figures 16 and 17 for both the CVD and the ICVI processes. The experimental CVD results permitted to determine in either case two distinct domains. The apparent reaction orders are equal to 1 for the minor reactant species and zero for the major one that appears to be preferentially adsorbed. 


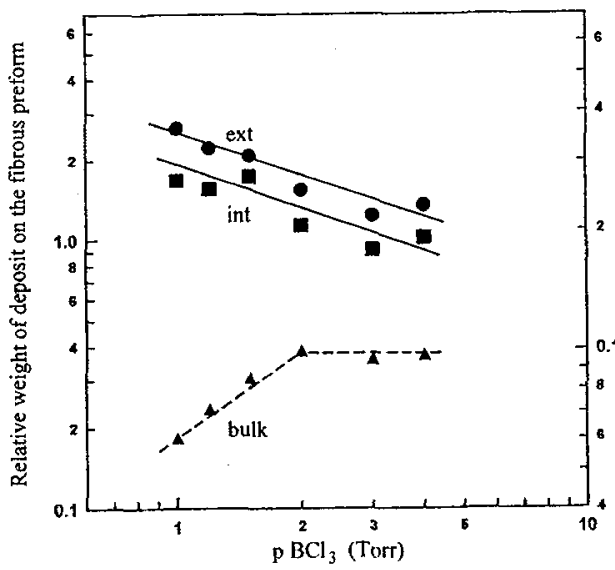

Figure 16 : Influence of the $\mathrm{BCl}_{3}$ partial pressure on the relative weight of deposit $(\Delta \mathrm{m} / \mathrm{m})$ on the bulk substrate and in the fibrous preform (in the internal and external parts) obtained for $\mathrm{T}=700^{\circ} \mathrm{C}, \mathrm{P}=8$ Torr.

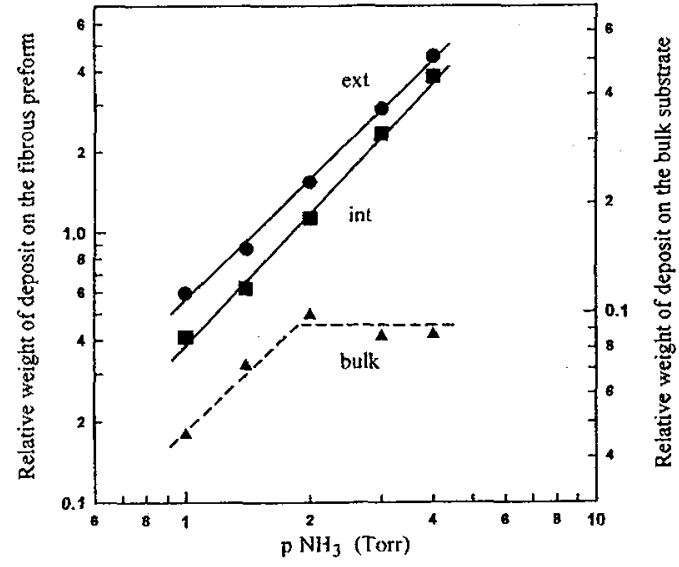

Figure 17 : Influence of the $\mathrm{NH}_{3}$ partial pressure on the relative weight of deposit $(\Delta \mathrm{m} / \mathrm{m})$ on the bulk substrate and in the fibrous preform (in the internal and external parts) obtained for $\mathrm{T}=700^{\circ} \mathrm{C}, \mathrm{P}=8$ Torr.

Regarding the CVI process, the nil apparent influences with respect to $\mathrm{HCl}$ and $\mathrm{Ar}$ were also observed, but the deposition kinetic behaviors appear different as a function of the reactant partial pressures. From figures 16 and 17, clearly the ICVI process is not purely chemical-rate limited in accordance to the previous conclusion from figures 14 and 15 . The deposition rates per surface unit can be estimated from the total surface of the bulk and the porous substrates, and the relative values of the CVD and ICVI rates can be compared. For example, figure 18 shows that the ICVI rates get closer to the CVD one as the inlet $\mathrm{NH}_{3}$ concentration increases.

Finally, different behaviors of the CVD and ICVI processes are observed. The deposition conditions can be varied as a function of either the processing parameters (inlet gas composition and total flow rate) or of the process type, CVD or ICVI. They produce variable relative rates of mass transfer and chemical kinetics and therefore different amounts of departure from equilibrium. A detailed study of the influence of various CVD and ICVI conditions on the BN structure is reported elsewhere [86]. It is shown that the CVD conditions quite depart always from equilibrium at $700^{\circ} \mathrm{C}$ and, classically, the deposit is badly organized. The ICVI process is somewhat more complicated as a function of various departures from chemical reactions completion. The structure can be optimized at this moderate temperature of $700^{\circ} \mathrm{C}$, in conditions where the ICVI process leads to a fairly good deposit uniformity [86].

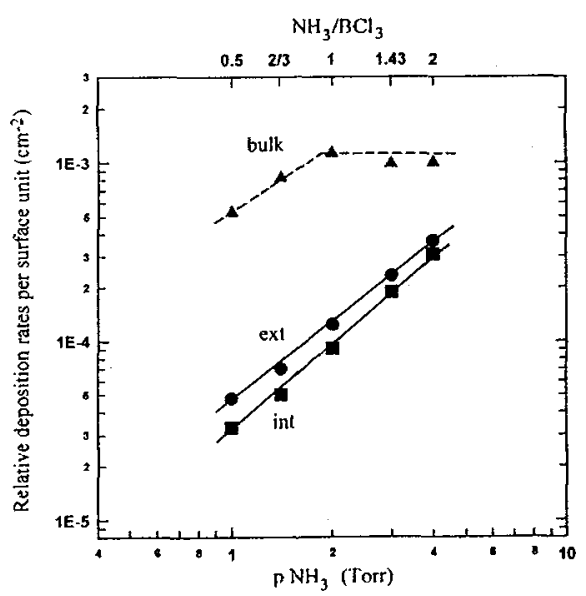

Figure 18 : Influence of the $\mathrm{NH}_{3}$ partial pressure on the relative deposition rate per surface unit $(\Delta \mathrm{m} /(\mathrm{m} . \mathrm{s}))$ on the bulk substrate and in the fibrous preform (in the internal and external parts) obtained for $\mathrm{T}=700^{\circ} \mathrm{C}, \mathrm{P}=8 \mathrm{Torr}$.

Figures $19 \mathrm{a}$ and $19 \mathrm{~b}$ present the worst and the best boron nitride microstructure that were obtained by CVD, in conditions of high departure from equilibrium, and by ICVI in optimized conditions respectively. In case of CVD, the interlayer spacing is $0.49 \pm 0.05 \mathrm{~nm}$ while it is only $0.35 \pm 0.02 \mathrm{~nm}$ for the ICVI sample (the standard value for well crystallized $\mathrm{BN}$ is $0.33 \mathrm{~nm}$ ). 


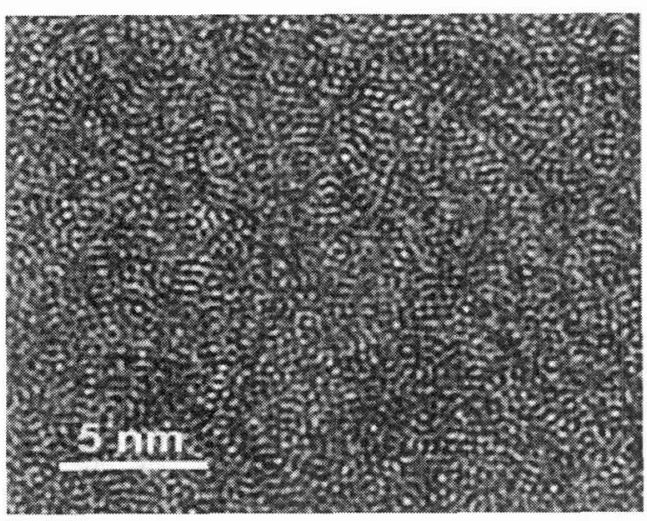

(a)

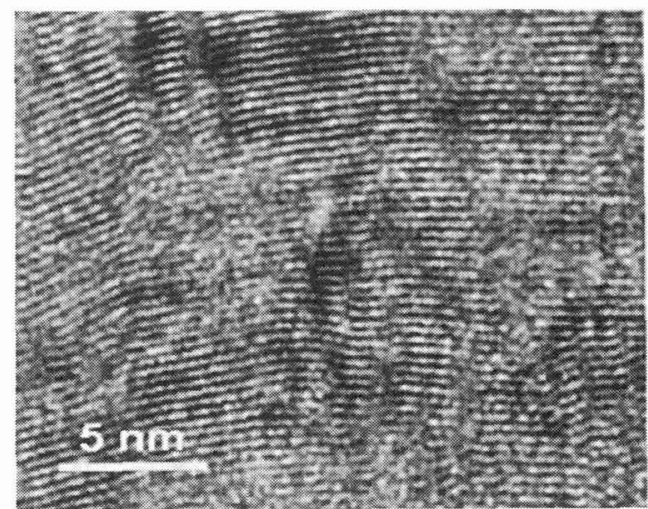

(b)

Figure 19: TEM lattice fringe images of boron nitride deposited at $700^{\circ} \mathrm{C}:$ a) by $\mathrm{CVD}$, b) by ICVI.

\section{Mechanical behavior of SiC/BN/SiC composites}

The mechanical properties at room and high temperature are detailed elsewhere [87]. It can be shown here that the 2D SiC/BN/SiC composites manufactured by ICVI with treated Nicalon ${ }^{\mathrm{TM}}$ fibers (proprietary treatment of the SEP) exhibit high tensile properties at room temperature (fig. 20) that are similar to the properties of materials with a pyrocarbon interphase. Static fatigue testings in air at $600^{\circ} \mathrm{C}$ were carried out on materials with various BN thicknesses. Two specimens of each composite were tested using a constant applied load to determine the time to cause specimen fracture as a function of the applied stress. Figure 21 compares the minimum time to cause failure of the different materials to the results obtained on a classical composite with a pyrocarbon interphase (both samples of the composite made with a $0.2 \mu \mathrm{m} \mathrm{BN}$ interphase were not fractured after more than 310 hours at $150 \mathrm{MPa}$ ). This fatigue test confirms the better behavior of the $\mathrm{SiC} / \mathrm{BN} / \mathrm{SiC}$ in oxidative atmosphere.

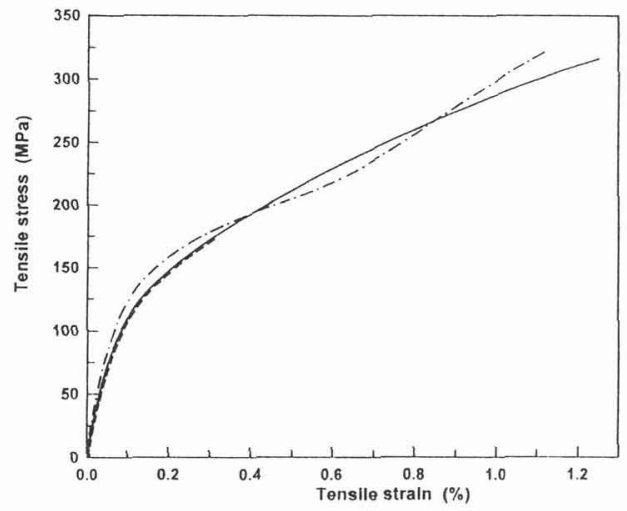

Figure 20 : Tensile stress-strain curves for $2 \mathrm{D} \mathrm{SiC} / \mathrm{BN} / \mathrm{SiC}$ with untreated (-- ) and treated fibers (--) both with $0.5 \mu \mathrm{m}$ $\mathrm{BN}$, and treated fibers with $0.2 \mu \mathrm{m} \mathrm{BN}(-\cdot)$.

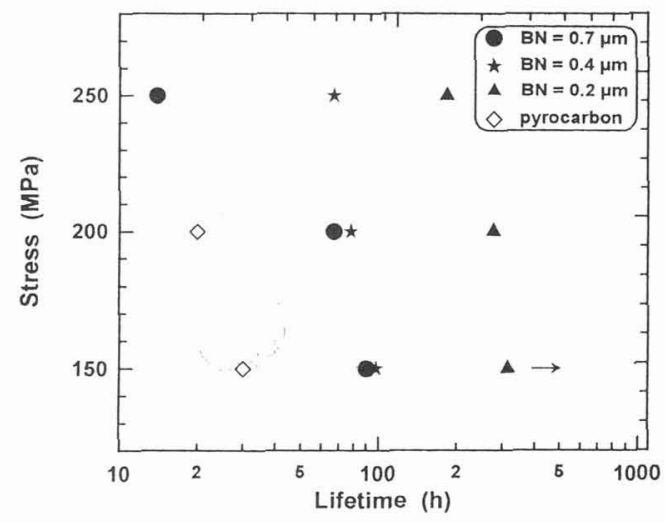

Figure 21: Influence of applied flexure stress on the time to cause fracture of $2 \mathrm{D} \mathrm{SiC} / \mathrm{C} / \mathrm{SiC}$ and $2 \mathrm{D} \mathrm{SiC} / \mathrm{BN} / \mathrm{SiC}$ composites with different interphase thicknesses.

\section{Remarks on the interphase processing}

The mechanical properties can be a function of both the presence of interfacial sublayers and the interphase microstructure. Appropriate pretreatments or careful attention to the initial interaction between 
the fibers and the gaseous phase used for interphase deposition are necessary. In other respects, it has been shown that the ICVI or PCVI [68] processes can be used at moderate temperature while obtaining wellorganized deposits. The CVD processing of $\mathrm{BN}$ is generally carried out at a higher temperature than here, directly on tows [84], such as good results might also be obtained.

More complex interphases derived from boron nitride are also considered to increase the oxidation and moisture resistance, like ternary solids [88]. However more evaluations of the final properties of the composites are still necessary. To elaborate such materials or compositional gradient layers or multilayers coatings, the advantages of ICVI would be obvious when compared to deposition by CVD on either stationary (in term of amount of fibers that could be coated) or moving tows (in term of processing complexity), also when it is compared to other infiltration processes as shown previously.

\section{CONCLUSION}

The potential large applications of ceramic composites require the preservation of their thermomechanical properties for long duration, in oxidative environments, under high temperature fatigue conditions and/or thermal cycling. This implies that the fibers and matrix properties, cracks deviation and load transfer at the fiber-matrix interface must be maintained. The oxidation resistance of non-oxide ceramic composites can be ameliorated by using protective external coatings, new matrices and interphases.

In most cases, the properties of each of these components are improved by associating different but complementary materials as multilayers or by using compositional gradient materials. The chemical vapor deposition processes are one of the most interesting way to elaborate such complex components. However all CVD and CVI techniques cannot be used, especially thermal gradient techniques, and the infiltration processes are limited to ICVI and eventually PCVI.

In spite of extensive works and notable progress, the oxidation resistance at the fiber-matrix interface remains insufficient. This is the critical problem to solve and researches on such interface property control are needed, especially by thermochemical treatment and deposition from the gaseous phase.

\section{ACKNOWLEDGEMENTS}

The authors gratefully acknowledge the financial support of the Société Européenne de Propulsion and Région Centre-Val de Loire, and the collaboration of $\mathrm{Y}$. Boussant and $\mathrm{C}$. Clinard. They are also thankfull to Drs C. Robin-Brosse and S Goujard from SEP for valuable discussions

\section{REFERENCES}

[1] - R.E. Tessler and J. A. DiCarlos, in High Temperature Ceramic Matrix Composites, R. Naslain, J. Lamon and D. Doumeingts Eds., (Proc. 6th Europ. Conf. on Comp. Mat.), Bordeaux, Woodhead Pub. Limited (1993) pp.33-50.

[2] T. B. Ramakrishna, A. Garg and D. R. Hull, Advances in Ceramic-Matrix Composites II, edited by J. P. Singh and N. P. Bansal, Ceramic Transactions, 46 (1994) 3-16.

[3] K. M. Prewo, Ceram. Bull., 68 (1989) 395-400.

[4] A. G. Evans and D. B. Marshall. Acta Metall., 37 (1989) 2567-83.

[5] R. J. Kerans, Scripta Metal. et Mater., 32 (1995) 505-509.

[6] R. A. Lowden and K. L. More, Mat. Res. Soc. Symp. Proc; 170 (1990) 205-214.

[7] R. Naslain, O. Dugne, A. Guette, J. Sevely, C. Robin-Brosse, J. P. Rocher and J. Cotteret, J. Am. Ceram. Soc., 74 (1991) 2482-88.

[8] M. P. Bacos, J. de Phys. IV, Colloque C7, supplément au J. de Phys., 3 (1993) 1895-1903. 
[9] A. W. More, M. B. Dowell, E. R. Stover and L. D. Bentsen. presented at the 19th annual Cocoa Beach Conference on Composites, Advanced Ceramics Materials and Structures, Jan. 8-12, 1995, Cacoa Beach, Fla. (USA).

[10] D. W. Mc Kee, Carbon, 24 (1986) 737-741

[11] C. E. Chang, Mat. Res. Bull., 6 (1971) 1287-

[12] W. J. Lackey, in Chemical Vapor Deposition/1987, G. W. Cullen and J. M. Blocher Jr. Eds, The Electrochemical Society Proceedings Series, Pennington, NJ (1987) pp. 1008-1027.

[13] T. Hirai, in Proc. 19th Univ. Conf. on Ceramic Sci., R.F. Davis, H Palmour III and R.L. Porter Eds., Plenum Press, NY (1984) pp. 329-345.

[14] K. Hiraga, M. Hirabayashi, S. Hayashi and T. Hirai, J. Am. Ceram. Soc., 66 (1983) 539-542.

[15] T. Hirai, T. Goto and T. Sakai, in Proc. 19th Univ. Conf. on Ceramic Sci., R.F. Davis, H Palmour III and R.L. Porter Eds., Plenum Press, NY (1984) pp. 347-358.

[16] S. Zirinsky and E.A. Irene, J. Electrochem. Soc., 125 (1978) 305-314.

[17] D. P. Stinton, W.J. Lackey, R.J. Lauf and T.M. Besmann, Ceramic Eng. Sci. Proc., 5 (1984) 668-676.

[18] M. Touanen, F. Teyssandier, M. Ducarroir and J.L. Derep, Mater. Sci. Eng., A147 (1991) 239-247.

[19] W. J. Lackey, A. W. Smith and D. J. Twait, Ceramic Eng. Sci. Proc., 9 (1988) 1223-1232.

[20] W. Y. Lee, J. Am. Ceram. Soc., 74 (1991) 2136-40.

[21] W. Kowbel, in Proceedings of the 3rd Int. Symp. on Ceram. Mater. and Components for Enginer, Las Vegas, 1988.

[22] K. Bartsch, J. Mater. Sci., 26 (1991) 4318-22.

[23] S. Goujard, L. Vandenbulcke and H. Tawil, Thin Solid Films, 252 (1994) 120-130.

[24] S. Goujard, L. Vandenbulcke and H. Tawil, J. Mat. Sci., 29 (1994) 6212-6220.

[25] S. Goujard, L. Vandenbulcke and C. Bernard, Calphad, 18 (1994) 369-385.

[26] L. Vandenbulcke, in Chemical Vapor Deposition/1979. T.O Sedgwick and H. Lydtin Eds., The Electrochemical Society Proceedings Series, Pennington, NJ (1979) pp. 315-331.

[27] D.E. Rosner, R. Nagarayan, S.A. Gokoglu and M. Kori, in Chemical Vapor Deposition/1979, G.W. Cullen and I.M. Blocher Jr. Eds., The Electrochemical Society Procecdings Scries, Pennington, NJ (1987) pp. 61-80.

[28] S. Goujard, L. Vandenbalcke, C. Bernard, G. Blondiaux and J.L.Debrun, J. Electrochem. Soc., 141 (1994) $452-461$.

[29] S. Goujard, L. Vandenbulcke and C. Bernard, J. Europ. Ceram. Soc., in press.

[30] S. Goujard, L. Vandenbulcke and H. Tawil. Thin Solid Films, 252 (1994) 86-97.

[31] Y. Madec and L. Vandenbulcke, to be published.

[32] K. Brenneflek and H. Reich, Journal de Physique IV, Colloque C2 - 1 (1991) 467-474.

[33] P. E. Grayson and N. J. Archer, Ceram. Eng. Sci. Proc., 14 (1993) 832-839.

[34] F. Christin L. Héraud, J.J. Choury, R. Naslain, P.Hagenmuller, Proc, 3rd Eur. Conf. CVD. Neuchatel, Switzerland, H.E. Hintermann, Lab. Suis. Rech. Horl., 1980, pp. 154-161.

[35] E. Fitzer and R. Gadow, Ceram. Bull., 65 (1986) 326-335.

[36] F. Christin, R. Naslain and C. Bernard, in Chemical Vapor Deposition/1979, T.O Sedgwick and H. Lydtin Eds., The Electrochemical Society Proceedings Series. Pennington. NJ (1979) pp.499-514.

[37] R. Naslain and F. Langlais, High Temp. Sci., 27 (1990) 221-235.

[38] R. Naslain, J. Alloys and Compounds, 188 (1992) 42-48.

[39] R. Naslain, Ceramic-Matrix Composites, Ed. Blackie. Glasgow (UK), (1992) 199-244.

[40] R. Fedou, F. Langlais and R. Naslain, in Chemical Vapor Deposition/1990, K.E. Spear and G. W Cullen Eds., The Electrochemical Society Proceedings Series, Pennington. NJ (1990) pp. 513-524.

[41] J. Y. Rossignol, F. Langlais and R. Naslain, in Chemical Vapor Deposition/1984, McD. Robinson, G. W. Cullen, C. H. J. van den Brekel, J. M. Blocher Jr. Eds, The Electrochemical Society Proceedings Series. Pennington, NJ (1984) 596-614.

[42] E. Fitzer, D. Hegen, and H. Strohmeier, Rev. Int. Hautes Temp. Refract., 17 (1980) 23.

[43] N.H. Tai and T.W. Chou, J. Am. Ceram. Soc, 72 (1989) 414-420.

[44] T.L. Starr, Ceram. Eng Sci. Proc., 8 (1987) 951-957.

[45] S.M. Gupte and J.A. Tsamopoulos, J. Electrochem. Soc., 136 (1989) 1626-1638.

[46] R.P. Currier, J. Am. Ceran. Soc., 73 (1990) 2274-2280.

[47] G.Y. Chung, B.J. McCoy, J.M.Smith, D.E. Cagliostro and M. Carswell, Chem. Eng. Sci., 46 (1991) 723-733.

[48] G.Y. Chung and B.J. McCoy, J. Am. Ceram. Soc., 74 (1991) 746-751.

[49] G.Y. Chung, B.J. McCoy, J.M. Smith and D.E. Cagliostro, Chem. Eng Sci., 47 (1992) $311-323$.

[50] R.J. Melkote and K F. Jensen, Mat. Res. Soc. Symp. Proc., 168 (1990) 67-72. 
[51] S.V. Sotirchos, AIChE Journal, 37 (1991) 1365-1378.

[52] S.V. Sotirchos and M.M. Tomadakis. Mat. Res. Soc. Symp. Proc, 168 (1990) 73-78.

[53] N.H. Tai and T.W.Chou, J. Am. Ceram. Soc.. 73 (1990) 1489-1498.

[54] J.I. Morell, D.J. Economou and N.R. Amundson, J. Electrochem. Soc., 139 (1992) 328-336.

[55] L. Filipuzzi, R. Naslain and C. Jaussaud, J. Mat. Sci., 27 (1992) 3330-3334.

[56] J.M. Jouin, F. Lamouroux and R. Naslain, in High Temperature Ceramic Matrix Composites, R. Naslain, J. Lamon and D. Doumeingts Eds., (Proc. 6th Europ. Conf. on Comp. Mat.), Bordeaux, Woodhead Pub. Limited (1993) pp. 707-714.

[57] C. Vix-Guterl, J. Lahaye and P. Ehrburger, in High Temperature Ceramic Matrix Composites, R. Naslain, J. Lamon and D. Doumeingts Eds., (Proc. 6th Europ. Conf. on Comp. Mat.), Bordeaux, Woodhead Pub. Limited (1993) pp. 725-732.

[58] F. Abbé and J.L Chermant, Proc. 4th Int. Conf. on Creep and Fracture of Eng. Mat. and Structures, W. Wilshire and R.W. Evans Eds., The Institute of Metals, London (1990) pp. 439-448.

[59] R.N. Singh and A.R. Gaddipati, US patent $N^{\circ} 4889686$.

[60] R.N. Singh and A. Morrison, US Patent $N^{\circ} 4944904$.

[61] P.E. Gray, US Patent $\mathrm{N}^{\circ} 4894286$.

[62] S. Goujard, L. Vandenbulcke, J.Rey, J.L. Charvet and H. Tawil, EP Patent 483009.

[63] T.M. Besmann, R.A. Lowden and D.P. Stinton, in High Temperature Ceramic Matrix Composites, R. Naslain, J. Lamon and D. Doumeingts Eds., (Proc. 6th Europ. Conf. on Comp. Mat.), Bordeaux, Woodhead Pub. Limited (1993) pp. 215-229.

[64] D.P. Stinton, A.J. Caputo and R.A. Lowden, Ceram. Bull., 65 (1986) 347-350.

[65] T.M. Besmann, R.A. Lowden, D.P. Stinton and T.L. Starr, Journal de Plysique, Colloque C5, 50 (1989) 229-239.

[66] R.L. Beatty and D.V. Kiplinger, Nucl. Appl. Tech., 8 (1970) 488-495.

[67] K. Sugiyama and E. Yamamoto, J. Mater. Sci, 24 (1989) 3756-3762.

[68] P. Dupel, R. Pailler, X. Bourrat and R. Naslain, J. Mater. Sci., 29 (1994) 1056-1066.

[69] C. Droillard, Thesis $N^{\circ} 913$, University of Bordeaux (France), 1993.

[70] R.A. Lowden, K.L. More, O.J. Schwarz and N.L. Vaughn, in High Temperature Ceramic Matrix Composites, R. Naslain, J. Lamon and D. Doumeingts Eds., (Proc. Gth Europ. Conf. on Comp. Mat.), Bordeaux, Woodhead Pub. Limited (1993) pp. 345-352.

[71] J.M. Agullo, F. Maury and J.M. Jouin. Journa] de Physique IV, Colloque C2, 3 (1993) 549-556.

[72] J.M. Agullo, F. Maury, R. Morancho and R. Carles, Mater. Lett., 11 (1991) 257

[73] N.J. Archer, High Temp. Chem. Inorg. Ceram. Mater., special publication No. 30. F.P. Glasser and P.E. Potter Eds., The Chemical Soc., London, (1976) 167-181.

[74] T. Matsuda, J. Mater. Sci., 24 (1989) 2353-58.

[75] E.Y. Sun, S.R. Nutt and J.J. Brennan, J. Am. Ceram. Soc.. 77 (1994) 1329-39.

[76] B.A. Bender and T.L. Jessen, J. Mater. Res., 9 (1994) 2670-76.

[77] A.C. Adams, J. Electrochem. Soc., 128 (1981) 1378-79.

[78] R.N. Singh, in Chemical Vapor Deposition/1987, G. W. Cullen and J. M. Blocher Jr. Eds, The Electrochemical Society Proceedings Series, Pennington, NJ (1987) pp. 543-549.

[79] A.C. Adans and C.D. Capio, J. Electrochem. Soc., 127 (1980) 399.

[80] H. Hannache, R. Naslain and C. Bernard, J. Less-Common Metals, 95 (1983) 221-46.

[81] O. Dugne, Thesis No. 375, University of Bordeaux (France), 1989.

[82] S. Motojima, Y. Tamura and K. Sugiyama, Thin Solid Films, 88 (1982) 269-274.

[83] V. Cholet and L. Vandenbulcke, J. Am. Ceram. Soc.. 76 (1993) 2846-58.

[84] B. A. Bender, T. L. Jessen and D. Lewis III, J. Am. Ceram. Soc., 75 (1992) 1628-35.

[85] M. Leparonx and $L$. Vandenbulcke, to be published.

[86] M. Leparoux, L. Vandenbulcke and C. Clinard, to be published.

[87] M. Leparoux, L. Vandenbulcke, S. Goujard, C.Robin-Brosse and J.M. Domergue, to be presented at XCCM 10, Vancouver (1995).

[88] A.W Moore, H. Sayir, S.C. Farmer and G.N. Morscher, presented at the 19 th anmual Cocoa Beach Conference on Composites, Advanced Ceramics Materials and Structures, Jan. 8-12, 1995, Cocoa Beach, Fla. (USA). 